Pakistan Journal of Education

Vol.36, No.2, 2019, 43-61

\title{
Effects of Cooperative Learning Models on Prospective Teachers' Achievement and Equity
}

\author{
Zaheer Ahmad * \\ Nasir Mahmood ${ }^{* *}$
}

\begin{abstract}
The cooperative learning (CL) intervention was conducted to find out the effects of two conditions of CL on prospective teachers (PTs) achievement and equity. Cooperative learning was embedded in methods of teaching English course. Thirty five students enrolled in Master of Arts in English Language Teaching and Linguistics programme (MA ELTL) were the subjects of the study. The study employed counter balanced design. The main research questions were; (1) What is the difference in Prospective Teachers' (PTs) achievement after exposure to $\mathrm{CL}$ as compared to their previous CGPA? (2) Which model of CL is better for producing higher achievement? (3) Which CL model provides/ establishes equity (equal chances to succeed) to maximum number of students? Achievement tests and class quizzes were administered to obtain data. Paired samples t-test, Mann-Whitney U test and KruskalWallis test were carried out to answer the research questions. The findings suggest that CL significantly enhances PTs' achievement as compared to Traditional Instruction (TI). Both CL models are compatible to increase achievement and equity in TE. Learning together (LT) is more efficient and effective as compared to Student teams Achievement Divisions (STAD). The study opens doors for doing innovations and intervention in teacher education through different CL models.
\end{abstract}

Keywords: cooperative learning, STAD model, learning together, achievement, equity

\footnotetext{
Lecturer, Department of Distance, Non-Formal and Continuing Education, Allama Iqbal Open University, Islamabad. Email: zaheeredu1@gmail.com

** Professor, Faculty of Education, Allama Iqbal Open University, Islamabad. Email: mashir1@yahoo.com
} 


\section{Introduction}

During the last few decades, due to interventions and innovations in the field of education psychology, many instructional strategies/ methodologies were introduced and remained in practice for substantial period of time. However, few enjoyed such recognition and popularity as CL which as per Slavin (1996) was the most researched and used teaching strategy in the domain of educational research. Its developers, proponents and practitioners are fully convinced of its effectiveness as it affects positively on almost all notable variables. Marr (1997) is of the view that cooperative learning comprises instructional strategies in which students are assigned to heterogeneous groups to complete instructional activities. Cooperative learning structures focus on both academic and social development.

\section{Five Components of $\mathbf{C L}$}

According to developers of CL (Johnson \& Johnson, cited in Siegel 2005), a class session will be considered a CL session, if it has the following 5-componenets criteria:

1. Positive interdependence: developing a feeling among team members of sinking or swimming together.

2. Individual accountability: making each member responsible for his/her own learning.

3. Face to face interaction: team members are made to verbalize their thinking aloud and discuss target content with each other

4. Social skills: ensuring that students follow group norms, take turns, respect others' views and avoid conflicts.

5. Group processing: making sure that each team member is on the track showing on task behavior

The above mentioned CL components can be employed through different CL models.

\section{Rationale for Using CL in Teacher Education}

The purpose of pre-service training is to develop desired competencies, skills and dispositions among potential future teachers in order to transform them into committed and competent practitioners. The general assumption is that student teachers will practice the instructional strategies in their practical life with which they were taught and trained. Veennman, Benthem, Bootsma, Dieren and Kemp, (2002) suggest that if teacher educators are interested to produce CL practitioners, they must demonstrate its enactment in pre-service trainings. Sharan, (2002) also supports this notion and state that classroom practices of teachers are 
rooted back to the pedagogical skills and competencies they observed, experienced and learned during their teacher education programme. Thus, there was a need to do CL intervention in teacher education which may result both in high achievement as well as developing equity for all type of PTs. And consequently such interventions may produce potential CL practitioners in future. The present study is a significant step in this direction.

Cooperative learning has in built characteristics and mechanism that differentiate it from other teaching strategies. Success of CL largely depends upon two requirements (a) building equitable/ balanced teams and (b) employ 5 components of CL. Though different models of work under the umbrella of CL, they all promise to employ both of these requirements. Equal teams are composed in a way that each team has at least a high achiever, a low achiever and one or two average achievers.

The successful employing of these components results in the building of CL teams in which there are no or less chances of the availability of hitch hikers and/or work horses.

\section{Literature Review}

There had not been any teaching learning strategy in history that was explored and researched so extensively and intensively as CL and thousands of research studies were carried out at K-12, college and university level to investigate CL potential benefits and positive effects on a number of variables.

Synthesizing the research on CL, Storm and Storm, $(1998,1999)$ concluded that it develops skills of problem solving, promotes supportive attitude towards education, higher self-esteem, enhanced willingness to take difficult initiatives, recognition of cultural diversity and positive interpersonal relations among friends.

Siegel (2005) says that because of the capacity to enhance students' achievement and development of social skills, CL has been recommended for school transformation. Johnson, Johnson and Smith (2007) concluded that there is substantial research which provides evidence that CL work well in college classes. Over more than three hundred research studies conducted at college and adults' levels reveals that $\mathrm{CL}$ is one of the best instructional strategy available to maximize students' learning achievement (especially of highly complex or difficult material) and long-term retention. In addition, cooperative learning is a central procedure for creating positive interpersonal relationships and personal and academic support promoting greater psychological health and well-being (including self esteem and social competencies), and 
developing positive attitudes towards the post secondary experience, and inculcating civic values.

Research also reveals that CL makes school learning experience meaningful (Vermette \& Foote, 2001) and increases mathematics achievement (Tarim \& Akdaniz, 2007). Saleh (2011), Aksoy and Doymus (2011) and Aydin \& Biyikli (2017) also reported the positive effects of jigsaw method on elementary graders" science laboratory skills acquisition.

Sutherland, McMaster and Marshall (2003) are of the view that to maximize students' learning, the teacher must incorporate into their instruction the critical components of CL.

Laal and Ghodsi (2012) CL compared with competitive and individualistic efforts and concluded that CL produces higher achievement and greater productivity, more caring, supportive, and committed relationships; and greater psychological health, social competence, and self-esteem.

These are the skills and dispositions, we intend to develop in our PTs. However, due to the dominance of TI in teacher education as revealed by Cooper (1995) CL has not gained acceptance as alternative to TI and due to which TI has not availed maximum benefits of CL. Thus, we find few research studies in which CL effectiveness had been explored by researchers in teacher education.

Researchers are of the view that educators need to be guided by research support as to which methods are effectives at higher education (Jefferey \& Purdom, 1995). Though sufficient literature is available for the selection of methods as CL, educators at university level also need to know which of the models of CL are effective and efficient as per their teaching philosophy and practicability. Thus, it is needed to explore the relative effectiveness of different CL models in teacher education.

Cooperative learning is such an instructional strategy whose effectiveness has been explored from different dimensions and on different variables. In a study Herrmann (2013) investigated the impact of CL on 140 students' engagement levels and found mixed results suggesting that $\mathrm{CL}$ groups can offer potentially valuable learning opportunities but teachers should be convinced that simply adopting CL without following its principles cannot bring desired results of CL.

Another study Tabatabaee, Rajabpour, Abdoos, Malekirad and Samadi (2013) compare the individual and collaborative learning of worked out examples in terms of impacts on cognitive load and transference of problem solving and found that mean of transference scores of collaborative group was significantly higher than individual group, but 
mean of cognitive load in collaborative group was significantly lower than individual group.

Castle (2014) in his doctoral research investigated the effect of $\mathrm{CL}$ on the development of need for cognition and concluded that participation in cooperative learning activities positively influenced the development of need for cognition among first-year college students. The study provides evidence that cooperative learning helps students develop opportunities to engage in the cognitive process, which can be evidence throughout their remaining life.

Different other studies, by exploring different dimensions of CL, highlighted that $\mathrm{CL}$ is matchless strategy to impact positively on students' different variables or to address different (Chandra, 2015; Gillies, 2016; Cornelius-Ukpepi, Aglazor \& Odey, 2016; Retnowati, Ayres \& Sweller, 2017; Le, Janssen \& Wubbels, 2018).

\section{Research Questions}

The study addressed the following research questions.

1. What is the difference in PTs achievement after exposure to CL as compared to their previous CGPA?

2. Which model of CL is better for producing higher achievement for all and in high, average and low achieving PTs?

3. How does CL establish equity (equal chances to succeed) to maximum number of students?

\section{Methodology of the Study}

This section of the study comprises design of the study, procedure and description of instruments.

\section{Design of the Study}

In the study, we employed counter balanced design in which all subjects receive all the treatments but in different order (Franekel \& Wallen, 2006). CL embedded intervention was carried out for full semester 28 sessions of 90 minutes each. Among these, 14 were conducted before and then conditions were reversed and remaining half lessons were delivered before final exam. During the intervention, students also took 13 quizzes one after each two sessions. At the end of each phase, students were administered achievement tests. The design of the study is depicted in the figure 1 .

The composition of session under both conditions is as under: 


\section{PHASE I}

\section{(Semester II)}

\section{Intervention}

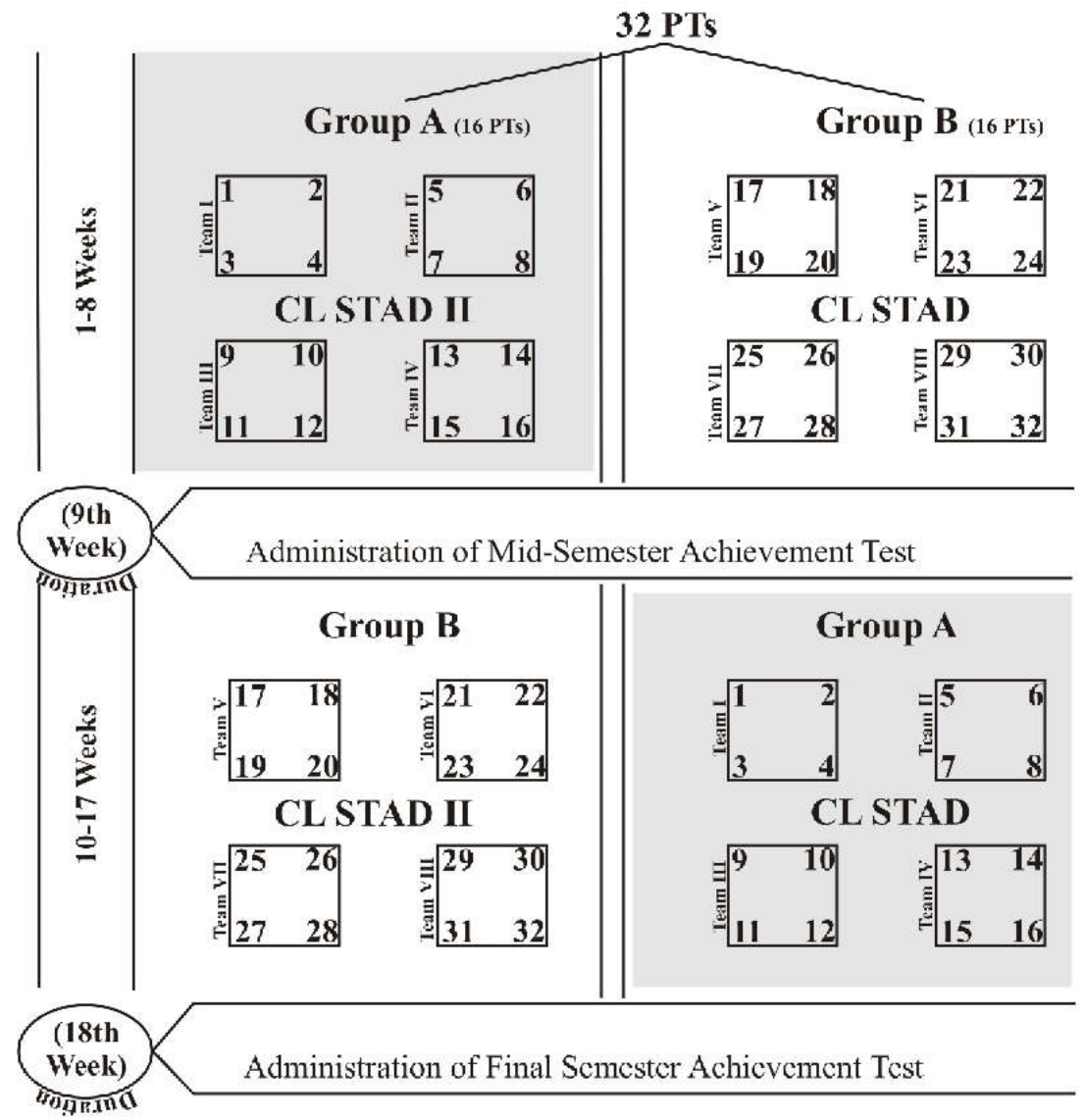

Figure 1: Design of the Study

\section{Experimental conditions}

The intervention was conducted through the following two experimental conditions after doing necessary modifications in the structured CL models in order to make them contextualized to local settings. 


\section{Learning Together (Group quiz condition)}

This was the modified CL model in which class is converted into teams. After teacher's presentation, students work in groups to learn and understand the material and after group work, take a team quiz or work on common work sheet. Team work is assessed as a single unit and students receive a grade or reward as a team and not individually (Johnson \& Johnson, 2002).

\section{Student Teams Achievement Divisions (STAD) (Individual quiz condition)}

It is a structured model of CL. The instructor initially delivers the lesson. Next, students' do the team work in small teams to learn the content. Individual quizzes are administered and teams are recognized/ rewarded on the basis of improvement scores of team members. In the present study, the model was used with the modification that instead of using improvement scores as suggested by (Venn, 2000), only the individual scores were used to form the team scores.

\section{Dependent Variables}

There were two dependent variables:

\section{Achievement}

The researchers have chosen achievement as one of the dependent variables because it is still a major concern in Asian countries as Pakistan. Johnson and Johnson, (2002) are of the view that academic achievement is one of the most important variables that CL affects positively. Justifying its importance, they further state that it provides bases for most of our decisions regarding instruction, management, policy making, curriculum and evaluation, etc. Thus, achievement is the first dependent variable. It was measured twice i.e. during and at the end of semester. Achievement in this study is defined as PTs scores in mid and final term tests in the methods of teaching English course.

\section{Equity}

Equity has been purposefully chosen because most of the intake of teaching candidates is either average or low performers in teacher education institutions (TEIs). As CL promises to provide equal/ maximum opportunities to succeed and excel, it was reasonable to test whether the claimed benefits of CL are applicable to low and high achiever prospective teachers. Slavin (1996) is of the view that CL is one of the most researched instructional strategy and there is still a lot to be explored about its potential benefits. Equity is a variable that has not been explored much previously. Regarding equity, only one article was 
available which addressed equity in CL classrooms. However, in this article, Cohen, Lotan, Scarloss and Arellano (1999) considered equity as access to all group members in group task and equitable relations among group members and concluded that developing equitable classroom is a need of the hour yet it is difficult to achieve. Besides this, equity was explored by the frequency of quiz positions of each team. Equity in this study was defined as equal opportunities to succeed and celebrate success. Meaning which to what extent average and low achieving PTs were also able to play this due role in task accomplishment and after competing were able to receive rewards.

\section{Instrumentation}

\section{Weekly quizzes}

Weekly quizzes were in built in the intervention. Each quiz was based on two sessions and comprised 6 MCQs, two short answer questions worth 10 marks (one quiz could not be administered). Their results were interpreted to explore evidences of equity in PTs.

\section{Achievement tests}

Achievements tests based on the taught content were developed by the researcher. The content validity of the tests was ensured by three professionals; two having experience in the ELTL field and one researcher. The weightage of instruments for the total evaluation was $80 \%(40 \%+40 \%)$. Both had the same format and marks distribution and contained 15 MCQs, 10 short answer questions and one restricted response item. Each test was worth 40 marks. Both had questions of knowledge and understanding levels as shown by the tables of specifications (see Annexure- $A$ ). The researcher utilized the scores of both the achievement tests for the main analysis and to sub-sequent the relevant research questions and for checking the relative effectiveness of both the CL models.

\section{Procedure of the Intervention}

At the start of intervention, subjects were matched as per their previous CGPA and were randomly assigned to either block A (LT condition first and STAD after mid-term) and block B (STAD condition first and LT condition after mid-term). Next, four teams were made in each condition having at least one high achiever, one low achiever and two average students. Total number of students were 32 instead of 35 in total as one three-member team was part of the treatment but was not included in the analysis. 
Next, the researcher (author 1) conducted first two sessions to teach social skills to get them familiarized with the cooperative learning processes. Next the intervention started and the teacher delivered the lessons simultaneously in both the conditions as teacher's presentation stage was similar for both conditions till the mid-semester. The detail of each session was as under:

1) Attendance $05 \mathrm{~min}$.

2) Teacher's presentation of the lesson to both the conditions. $40 \mathrm{~min}$.

3) Students group work in both the conditions. $35 \mathrm{~min}$

4) Individual /group quizzes (after two lessons) $10 \mathrm{~min}$

OR

4) Certificate distribution (after two lessons)

$10 \mathrm{~min}$

After 14 lessons, students in both the conditions took mid- term achievement test consisting of the content covered in 14 lessons. After mid semester, the experimental conditions were reversed.

\section{Results}

As per nature of research questions, different analyses were carried out by employing appropriate statistical techniques. The detail is as under:

In order to address research question 1 paired samples t-test was run to find out whether there was statistically significant difference between the PTs' previous CGPA (of $1^{\text {st }}$ semester) and current GPA in the methods course, after exposure to CL: The results one as under:

Table 1

Paired Samples t-test of GPA in this Course and CGPA of the Previous Semester

\begin{tabular}{lllllll}
\hline Levels & $\mathrm{N}$ & Mean GPA & $\mathrm{SD}$ & $\mathrm{d} f$ & $\mathrm{t}$-value & $p$ \\
\hline CGPA (PS) & 32 & 2.46 & 0.67 & 31 & $5.93^{* *}$ & 0.000 \\
GPA (EC) & 32 & 3.02 & 0.39 & & & \\
\hline$* * \mathrm{p}<0.001$ & & & & & &
\end{tabular}

Table 1 indicates that $t$-value (5.93) is significant at $\mathrm{p}<0.001$. It is evident that the current GPA $(\mathrm{M}=3.02, \mathrm{SD}=0.39)$ is significantly higher than the previous CGPA of the first semester $(\mathrm{M}=2.46, \mathrm{SD}=$ $0.67)$. 
Separate analysis was also done to explore which group among the three (high, average and low achievers) gained maximum benefit from the intervention and which gained least. This is depicted from table 2 .

Table 2

Descriptive Statistics of Gained GPA by Achievement Groups

\begin{tabular}{llll}
\hline $\begin{array}{l}\text { Achievement } \\
\text { Groups }\end{array}$ & $\mathrm{N}$ & Mean Rank (Gained) & SD \\
\hline High Achievers & 9 & 9.44 & 0.14 \\
Average Achievers & 11 & 14.23 & 0.39 \\
Low Achievers & 12 & 23.88 & 0.30 \\
\hline
\end{tabular}

It is evident from table 2 that gained mean rank of high achievers is 9.44 , average achievers' is 14.23 and low achievers' is 23.88 . It is evident that low achievers have the high mean rank and high achievers have the lowest mean ranks among the three.

To explore whether the gained GPA in methods course was statistically different among high, average and low achievers, the Kruskal-Wallis test was applied as suggested by Green, Salkind and Akey (2000).

Table 3

The Kruskal-Wallis Test for Gained GPA by Achievement Groups

\begin{tabular}{llllll}
\hline $\begin{array}{l}\text { Achievement } \\
\text { Groups }\end{array}$ & $\mathrm{N}$ & $\begin{array}{l}\text { Mean } \\
\text { Rank }\end{array}$ & $\begin{array}{l}\text { Chi-Square } \\
\left(\chi^{2}\right)\end{array}$ & $\mathrm{d} f$ & $p$ \\
\hline High & 9 & 9.44 & $13.176^{* *}$ & 2 & 0.001 \\
Average & 11 & 14.23 & & & \\
Low & 12 & 23.88 & & & \\
\hline
\end{tabular}

$* * \mathrm{p}<0.01$

Table 3 reflects that the chi-square $\chi^{2}$ value 13.18 is significant at $\mathrm{p}<0.001$. It is evident that the mean ranks of high, average and low achievers is significantly different from one another. For further analysis, Mann-Whitney U tests were carried out for pair-wise comparison.

Table 4

Pair-wise Comparisons regarding Gained GPA by Applying MannWhitney U Test

\begin{tabular}{|c|c|c|c|c|c|}
\hline $\begin{array}{l}\text { Achievement } \\
\text { Groups }\end{array}$ & $\mathrm{N}$ & $\begin{array}{l}\text { Mean } \\
\text { Rank }\end{array}$ & $\begin{array}{l}\text { Mann } \\
\text { U }\end{array}$ & Whitney & $p$ \\
\hline High Achievers & 9 & 5.78 & $7.00 * *$ & & 0.001 \\
\hline Low Achievers & 12 & 14.92 & & & \\
\hline Average Achievers & 11 & 8.23 & $24.50 *$ & & 0.011 \\
\hline Low Achievers & 12 & 15.46 & & & \\
\hline
\end{tabular}

$* \mathrm{p}<0.05, \quad * * \mathrm{p}<0.01$ 
Table 4 reflects that mean rank difference between high achievers and low achievers is statistically significant. Mann Whitney $\mathrm{U}$ value (7.00) is significant at $\mathrm{p}<0.01$. It is evident that the mean rank of low achievers (14.92) is significantly higher than the mean rank of high achievers (5.78). The table further reflects that the mean rank difference between average achievers and low achievers is statistically significant. Mann Whitney $U$ value (24.50) is significant at $p<0.05$. It is evident that the mean rank of low achievers (15.46) is significantly higher than the mean rank of average achievers (8.23).

\section{Achievement Results: STAD vs. STAD II}

For conducting analysis, Mann-Whitney U test was carried out separately on the scores of the subjects of group 'A' and group 'B' at mid-semester achievement test (see table 5).

Table 5

Mann-Whitney U Test for Differences of Mean Ranks

\begin{tabular}{llllll}
\hline Condition & $\mathrm{N}$ & Achievement Test & $\begin{array}{l}\text { Mean } \\
\text { Rank }\end{array}$ & $\begin{array}{l}\text { Mann- } \\
\text { Whitney U }\end{array}$ & $p$ \\
\hline STAD II & 16 & Mid-Semester & 16.53 & 127.50 & 0.993 \\
STAD & 16 & & 16.47 & \\
\hline
\end{tabular}

Table 5 reflects that Mann-Whitney U value (127.50) is not significant at $\mathrm{p}<0.05$. It is evident that PTs of group A under STAD II did not perform significantly better on mid semester achievement test (Mean Rank $=16.53$ ) than group B under STAD (Mean Rank = 16.47).

As the PTs in each group had achievement scores on both treatments and all the subjects had undergone both the treatments alternatively, therefore, data was also analyzed by paired samples t-test. For this analysis, the data was arranged by putting all subjects' scores under STAD and under STAD II conditions. (Total mid and final term scores in STAD II and Total mid and final term scores in STAD condition).

Table 6

Results of Paired Samples t-test across both Conditions

\begin{tabular}{llllllll}
\hline Models of CL & $\mathrm{N}$ & Achievement test & $\mathrm{d} f$ & Mean & $\mathrm{SD}$ & t-value & $p$ \\
& & & & & & & \\
\hline STAD II & 32 & Mid + Final & 31 & 27.44 & 3.93 & 0.15 & 0.880 \\
STAD & 32 & Mid + Final & & 27.34 & 4.54 & & \\
\hline
\end{tabular}


Table 6 reflects that $t$-value $(0.15)$ is not significant at $p<0.05$. It is evident that the achievement scores of all PTs in STAD II (M $=27.44$, $\mathrm{SD}=3.93$ ) are not significantly different from the achievement scores of all PTs in STAD model $(\mathrm{M}=27.34, \mathrm{SD}=4.54)$.

In order to investigate which of the two CL models had a significant effect on the achievement of high, average or low achievers (PTs), there was further breakdown of the analysis by achievement groups (see table 7). For this analysis, non-parametric analysis was carried out.

Table 7

Comparison of STAD vs. STAD II by Achievement Groups

\begin{tabular}{llllll}
\hline \multirow{2}{*}{ PTs by Achievement } & \multirow{2}{*}{$\mathrm{N}$} & \multicolumn{2}{l}{ Mean Ranks } & \multirow{2}{*}{$\mathrm{Z}$} & \multirow{2}{*}{ STAD } \\
\cline { 3 - 5 } & & STAD II & STAD & & \\
\hline High Achievers & 9 & 5 & 3.25 & -0.171 & 0.865 \\
Average Achievers & 11 & 6.38 & 4.92 & -0.207 & 0.836 \\
Low Achievers & 12 & 7.25 & 4.33 & -0.154 & 0.878 \\
\hline
\end{tabular}

Table 7 indicates that application of two related samples (Wilcoxon Signed Ranks Test) reveals that there was no significant difference between high achievers mean ranks in STAD II (5) and STAD (3.25) with $\mathrm{Z}$-value $(-0.171), \mathrm{p}=0.865$. There was also no significant difference between average achievers scores in STAD II (6.38) and STAD (4.92) with $Z$-value $(-0.207), p=0.836$. The table further reveals that low achievers' mean ranks were also not significant different in STAD II (7.25) and in STAD (4.33) with z-value (-0.154), p $=0.878$.

The results revealed that there were no significant differences in the three analyses carried out. It is evident that there was an effect of CL on PTs' achievement but no effect of any particular CL model.

\section{Team Achievement and Equity}

Studies have rarely reported in published research the concept of 'equal opportunity to succeed' even if the concept has been explored. The researcher utilized team recognition by using quiz scores component to explore whether all teams had their due share in winning the quizzes. Thus, even average and low achievers of teach team had equal chances to win and defeat other teams and celebrate success which is not witnessed in TI. When explored the results of the 13 quizzes, it was found that almost all students including 12 low achievers of the class took their team to victory stand in a range of three times to ten times. Thus, they also tested success and were acknowledged by their team member and 
teachers. So, CL intervention resulted in providing equal opportunities to learn, improve and share knowledge with other team members and receive support and guidance by their high achieving and better team member on the perception that no team can win and defeat other teams without the maximum efforts and support of each team member. Low achievers also developed the feelings that they are important and deserve success too. After each quiz, two top teams from each group 'A' and 'B' were appreciated and awarded team recognition certificates. The salient features of the intervention were that each team member was ensured to contribute in team success and come to the stage to receive the certificates. Thus, after each quiz, four teams were position holders. Out of total possible team positions (52) a total of 45 team positions were earned by the different CL teams. Seven positions could not be obtained by any team due to not fulfilling the criteria i.e. a presence of at least 3 members of a team and (b) obtaining at least $50 \%$ marks as a team. Team positions obtained by each team are given in the following figure.

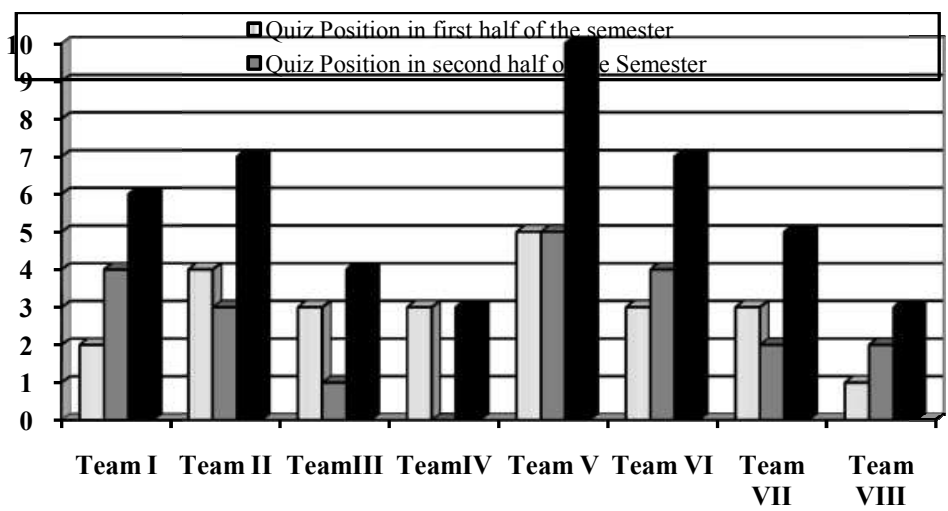

Figure 2: Frequency of team positions in class quizzes demonstrating equity

Figure 2 reveals the whole picture of the team positions in quizzes. Frequency of positions has been presented against each team. The figure reveals that among the eight teams, the most successful is team 5 with ten team positions in the quizzes. This suggests that all members of team 5 including high, average and low achievers were able to reach at the victory stand ten times to celebrate success during a semester. On the other hand, team 4 and team 8 were least successful as they could manage to win the quizzes not more than three times each. In other words, all teams covering each and every PT of the class celebrated success at least three times during the semester. 


\section{Discussion}

The study investigated the relative effectiveness of two modified CL models: STAD (individual quizzed condition) and LT (group quizzed condition) on students' achievement and equity. The study established the effectiveness of $\mathrm{CL}$ over traditional instruction. Regarding relative effectiveness of both models, it was found that PTs gained more achievement scores in STAD condition but these were not statistically significant. The reasons was that the students in the STAD condition took individual quizzes after the group work and thus were made personally accountable for their learning so they performed better as compared to PTs in other condition. Whereas students in the LT condition took team quizzes after the group work.

One explanation, supporting the findings is that in higher /teacher education, students are matured and self-disciplined enough and it is less likely that they become hitch hikers or work horses during group work. This argument is consistent with Authors (2010) study in which they found that the pre-service teachers reported more active and enjoyable CL learning experience in loosely structured CL model as compared to TI and highly structure STAD model.

The study established equity in teacher education by providing opportunities to participate in class or group activities as suggested by (Cohen et al, 1999) and equal opportunities to succeed as per our point of view that every student reached at the stage to receive the certificates (team recognition) at least three times. Thus, both CL models provided evidence to promote equity in teacher education. The study suggests that every type of students can get benefits from CL and CL is the most efficient model of catering for the individual differences of the students. Its potential to develop equity provides all students in the class to reach at the victory to enjoy success. No other method or technique has such a mechanism to develop achievement motivation to all students in the class irrespective of their achievement level.

\section{Conclusion}

To conclude, we can say that CL results in higher achievement in TE. Both models LT and STAD have the potential to be used in TE. Cooperative learning used systematically provided equity to every type of PTs which is not possible in any other instructional strategy. Thus, we can say that it is convenient for teacher educators to use LT model rather than STAD model and achieve the same benefits of STAD with less effort, time and energy. It is also practicable even in small classrooms and saves time, creates less problems of management and sitting 
arrangement. As it was somewhat difficult to fulfill the requirements of the STAD condition for the teacher (administering and checking of individual quizzes), it is suggested that university teachers can use STAD occasionally alongwith LT to achieve maximum benefits of both the models. It should also be ensured that PTs will not know how they would be tested group vs. individually. Imposing this condition of random selection of quiz type will ensure individual accountability among PTs. The STAD model can also be used before or after the use of LT. Future researches should explore whether such interventions (exposure to CL) in teacher education affect on their teaching behavior after their graduation. As researchers Vennman et al. (2002) suggest that if they are taught through CL methods, it is likely that it will become part of their future teaching. The study has implications for researchers and CL proponents to work on possibilities to establish simplified/ modified versions of existing CL models so that the use of CL is increased in other than researchers' controlled settings and novice users of CL may feel comfortable while using those models in the beginning.

\section{Acknowledgement}

The data of this research paper is a part of $\mathrm{PhD}$ research work of Author 1 which was funded by Higher Education Commission (HEC) of Pakistan in lieu of HEC Indigenous Fellowship Program for PhD-III earned by won by the author (Zaheer, 2012).

\section{Annexure A}

Table of Specification of Mid-Semester Achievement Test

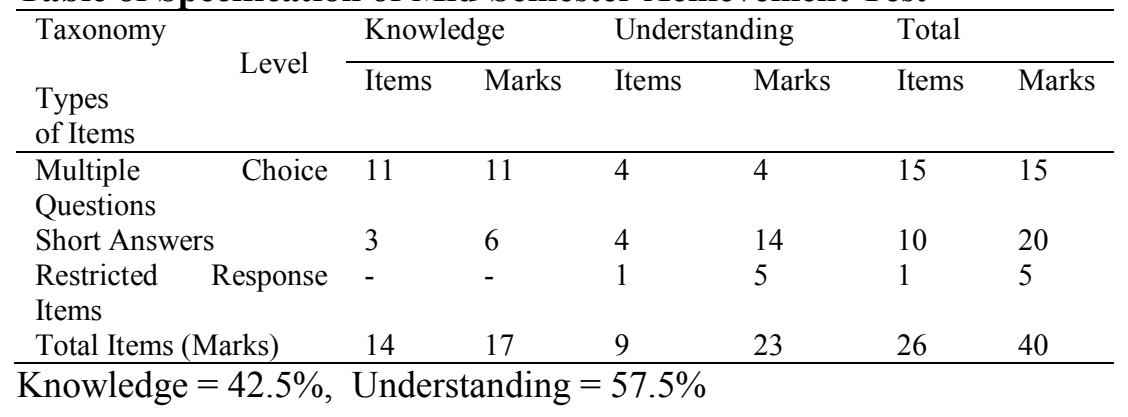


Table of Specification of Final Semester Achievement Test

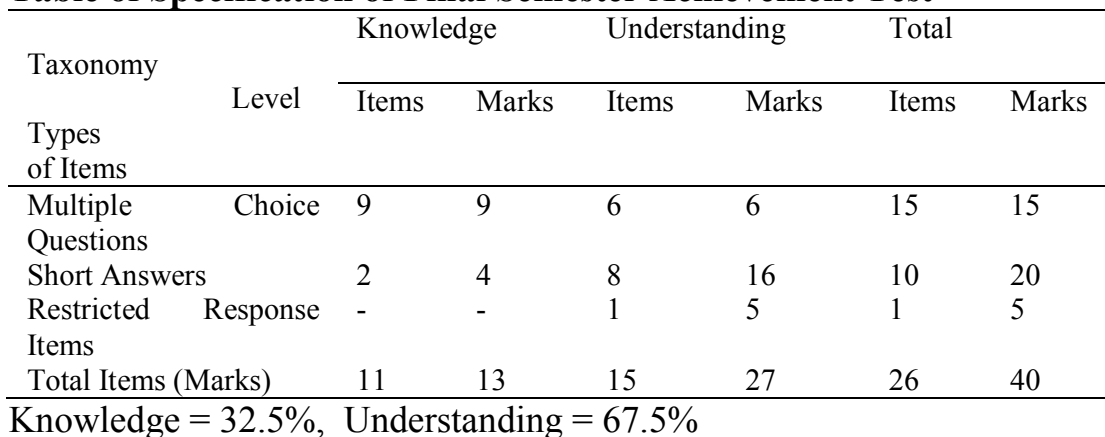




\section{References}

Aksoy, G., \& Doymuş, K. (2011). Fen ve teknoloji dersi uygulamalarında işbirlikli okuma-yazma-uygulama tekniğinin etkisi. Gazi Eğitim Fakültesi Dergisi, 31(2), 381-397.

Authors, (2010). Effects of cooperative learning Vs traditional instruction on prospective teachers' learning experience and achievement. Ankara University, Journal of Faculty of Educational Sciences, 43(1), 151-164.

Aydin, A., \& Biyikli, F. (2017). The effect of jigsaw technique on the students' laboratory material recognition and usage skills in general physics laboratory-I course. Universal Journal of Educational Research, 5(7), 1073-1082.

Castle, T. D. Jr. (2014). The impact of cooperative learning on the development of need for cognition among first-year college students. (Unpublished $\mathrm{PhD}$ Dissertation), University of Iowa. https://doi.org/10.17077/etd.8j7n5q43

Chandra, R. (2015). Collaborative learning for educational achievement. IOSR Journal of Research and Method in Education 5(2), 1-4.

Cohen, E. G., Lotan, R. A., Scarloss, B. A., \& Arellano, A. R. (1999). Complex instruction: Equity in cooperative learning classrooms. Theory into Practice, 38(2), 80-86.

Cooper, J. L. (1995). Cooperative learning and critical thinking .Teaching of Psychology, 22(1), 7-9.

Cornelius-Ukpepi, B. U., Aglazor, G. N., \& Odey, C. O. (2016). Cooperative learning strategy as tool for classroom management. Advances in Multidisciplinary Research Journal, 2(2), 67-76.

Fraenkel, J. R., \& Wallen, N. E. (2006). How to Design and Evaluate Research in Education. New York: McGraw. Hill Companies, Inc.

Gillies, R. M. (2016). Cooperative Learning: Review of Research and Practice. Australian Journal of Teacher Education, 41(3), 39-54. 
Green, S. B., Salkind, N J., \& Akey, T. M (2000). Using SPSS for Windows: Analyzing and Understanding Data ( $2^{\text {nd }}$ ed.). Upper Saddle River, NJ: Prentice-Hall.

Herrmann, K. J. (2013). The impact of cooperative learning on student engagement: Results from an intervention. Active Learning in Higher Education, 14(3), 175-187.

Jefferey, D., \& Purdom, D. M. (1995). A comparison of lecture, cooperative learning and programmed instruction at the college level. Studies in Higher Education, 20(3), 341-349.

Johnson, D. W., \& Johnson, R. T. (2002). Learning together and alone: Overview and meta analysis. Asia Pacific Journal of Education, 22(1), 95-105.

Johnson, D. W., Johnson, R. T., \& Smith, K. (2007). The State of Cooperative Learning in Post Secondary and Professional Settings. Educational Psychology Review, 19(1), 15-29.

Laal, M., \& Ghodsi, S. M. (2012). Benefits of collaborative learning. Procedia-Social and Behavioral Sciences, 31, 486-490.

Le, H., Janssen, J., \& Wubbels, T. (2018). Collaborative learning practices: teacher and student perceived obstacles to effective student collaboration. Cambridge Journal of Education, 48(1), 103-122.

Marr, M. (1997). Cooperative learning: A brief review. Reading \& Writing Quarterly, 13(1), 7-20

Retnowati, E., Ayres, P., \& Sweller, J. (2017). Can Collaborative Learning Improve the Effectiveness of Worked Examples in Learning Mathematics? Journal of Educational Psychology, 109(5), 666-679.

Saleh, T. A. (2011). Statistical analysis of cooperative strategy compared with individualistic strategy: an application study. The Journal of Effective Teaching, 11(1), 19-27.

Sharan, S. (2002). Differentiating methods of cooperative learning in research and practice. Asian Pacific Journal of Education, 22(1), 106-116. 
Siegel, C. (2005). Implementing a research-based model of cooperative learning. The Journal of Educational Research, 98(6), 339-349.

Slavin, R. E. (1996). Research on cooperative learning and achievement: What we know, what we need to know. Contemporary Educational Psychology, 21, 43-69.

Storm, R. D., \& Storm, P. S. (1998). Student participation in the evaluation of cooperative learning. Community College Journal of Research and Practice, 22(3), 265-278.

Storm, R. D., \& Storm, P. S. (1999). Making student accountable for team work Community College Journal of Research and Practice, 23(2), 171-182.

Sutherland, K. S., McMaster, K. L., \& Marshall, J. (2003). Maximizing the benefits of cooperative learning for students with learning and/or behavior problems. Beyond Behavior, 13(1), 12-16.

Tabatabaee, S. M., Rajabpour, M., Abdoos, F., Malekirad, A., \& Samadi, F. (2013). The impacts of individual and collaborative learning of worked out examples on problem-solving transference and cognitive load. Advances in Applied Science Research, 4(6), 219-224.

Tarim, K., \& Akdeniz, F. (2007). The Effects of Cooperative Learning on Turkish Elementary Students' Mathematics Achievement and Attitude towards Mathematics using TAI and STAD Methods, Published online: 17 July 2007, \# Springer Science + Business Media B.V.

Veenman, S., Benthum, N. V., Bootsma, D., Dieren, J. V., \& Kemp, N. V. D. (2002). Cooperative learning and teacher education. Teaching and Teacher Education, 18, 87-103.

Venn, J. J. (2000). Assessment in Inclusive Settings. Assessing Students with Special Needs ( $2^{\text {nd }}$ ed.). New Jersey: Prentice Hall Inc.

Vermette, P., \& Foote, C. (2001). Constructivist Philosophy and Cooperative Learning Practice: Toward Integration and Reconciliation in Secondary Classrooms. American Secondary Education, 30(1), 26-37. 
William, K. D. (1996). Cooperative learning: A new direction. Education, $117(1), 39-42$.

Zaheer, A. (2012). Impact of cooperative learning experience on preservice teachers' achievement and teaching behavior. (Unpublished doctoral dissertation). Institute of Education and Research, University of the Punjab, Lahore.

\section{Citation of this Article:}

Ahmad, Z., \& Mahmood, N. (2019).Effect of cooperative learning models on prospective teachers' achievement and equity. Pakistan Journal of Education, 36(2), 43-61 